\title{
El militarismo desarrollista en \\ América Latina
}

Alberto SEPÚlYedA, M. A., M. A., L. D., actualmente en la Fletcher School of Law and Diplomacy, Medford, Massachusetts, siguiendo estudios para el doctorado en Relaciones Internacionales. Profesor de Politica Latinoamericana en la Universidad de Northeastern, Boston, Massachusetts.

\section{INTRODUCCION}

En 1964, el Gobierno del Presidente Goulart fue derrocado por un golpe militar. Por primera vez los uniformados brasileños especificaban que no entregarían el poder a otro político civil. Ahora corresponderia a los ex alumnos de la Escola Superior de Guerra asumir la tarea de "modernizar" el vasto país sudamericano.

En los años siguientes, en Argentina, Perú y Bolivia surgieron gobiernos militares imbuidos de la misma confianza en su capacidad para crear una moderna sociedad industrial. En cierta medida, los militares panameños guardan relación, en el plano ideológico, con sus colegas sudamericanos. Sin embargo, se trata de una Policía militarizada, en lugar de Fuerzas Armadas propiamente tales. Por esta razón, no hemos analizado con mayor profundidad su experiencia.

El objeto de este trabajo es clarificar el modelo de sistema político que se proponen desarrollar los grupos militares señalados. Para ello, hemos destinado especial atención al estudio de su pensamiento con el fin de determinar con claridad su ideología y predecir tanto su eventual evolución futura, como la posibilidad de éxito del modelo de desarrollo.

Debido a que nuestra intención es la de tratar de pronosticar la suerte de estos regimenes y con el fin de clarificar el problema del militarismo latinoamericano moderno, hemos incluido en este trabajo antecedentes históricos sobre las dictaduras tradicionales y algunos de los temas que han originado mayor discusión, como, por ejemplo, la ayuda militar norte- 
E S T U D I O S I N T E R N A C I O N A L E S

americana, el tipo de reformismo propiciado por los militares, sus esquemas nacionalistas y sus posibilidades de mantener el poder. Guando este trabajo ya estaba terminado, el General Onganía fue derrocado por sus colegas, dándose así una de las hipótesis de este estudio. Quedará por determinar si este cambio significa el fin de la concepción militarista del desarrollo en el país del Plata, o si se trata de un simple cambio de personas.

No pretendo, en este trabajo, sentar conclusiones científicas acerca de los militares. Mi intención es la de presentar, con la mayor claridad posible, el problema actual y extraer algunas hipótesis que sirvan para formular una política en relación con los gobiernos militares. La utilidad del ensayo es que este tipo de análisis es relativamente escaso. En general la bibliografía sobre el militarismo latinoamericano tiende a centrarse en algunas definiciones conceptuales que no permiten elaborar políticas claras, ni prever la evolución de estos gobiernos.

En la medida que este trabajo aporte alguna luz frente a los nuevos desafíos políticos que presenta el militarismo desarrollista este ensayo se justifica.

\section{LOS MLITARES POPULISTAS (I 939-1958)'}

En líneas generales, podemos establecer que, desde $193^{\circ}$ a $195^{8}$, la intervención militar tuvo ciertas características comunes. Se dio el tipo de dictadura que hemos denominado "Populista".

Las características principales de este tipo de intervención militar fueron, en general, las siguientes:

El gobierno era dominado por un caudillo respaldado, principalmente, por el Ejército. La Marina y la Fuerza Aérea no proporcionaron ningún dictador en este período.

El caudillo tendió a dar, en algunos casos, los primeros pasos hacia la industrialización y su política tuvo una orientación marcadamente urbana. En materia agraria, pese a no contar con la simpatía de la oligarquía, tendió a mantener el statu quo. En este período no se iniciaron proyectos tendientes a una redistribución de la propiedad de la tierra.

Los dictadores populistas promovieron la creación de sindicatos controlados por el Gobierno y se demostraron francamente partidarios de la

${ }^{1}$ El periodo se establece tomando en consideración el año en que Getulio Vargas tomó el poder en Brasil y el año en que Batista fue derrocado por Castro. 
inversión extranjera, especialmente en productos primarios, como un medio de obtener el desarrollo.

La propiedad privada fue considerada el motor de la economía y, en general, el Estado no asumió un papel destacado en la creación de industrias, limitándose a ofrecer garantías para el mejor funcionamiento de los capitalistas particulares. La excepción más notable, en esta materia, fue la política seguida por Perón en lo relativo a la creación de nuevas industrias, la mayoria de ellas basadas en conceptos de seguridad y de potencialidad militar ${ }^{2}$.

Las relaciones con Estados Unidos, nuevamente salvo el caso de Perón, fueron estrechas. En algunos casos se llegó al servilismo.

El nivel de sofisticación, en conocimientos politicos, económicos y sociales, fue, en general, bastante bajo. Tampoco aparecieron cuadros técnicos de calidad que pudieran suplir esta limitación. Por el contrario, en la mayoría de las oportunidades, tuvieron la oposición de los tecnócratas, estudiantes e intelectuales de la época.

Posiblemente, por acentuar su linea "populista" cayeron en un desprecio de los intelectuales pretendiendo oponer un sentimiento popular contra el refinamiento de la intelectualidad a la que acusaron de estar ligada a las oligarquías. Una expresión de este sentimiento se dió en el período de Perón bajo el lema de "Alpargatas si, libros no"3.

Otro de los elementos importantes en su orientación fue el "descubrimiento" de los sectores marginales o del lumpenproletariat. Pérez Giménez construyó diversas poblaciones modernas destinadas a alojar a los habitantes de los "ranchitos" de Caracas. En el caso de Odría, durante las elecciones presidenciales de 1962 , su candidatura obtuvo el triunfo en Lima, gracias al apoyo de los habitantes de las "barriadas" que aún recordaban los beneficios obtenidos durante su Administración.

La corrupción fue generalizada. Los "hombres fuertes" y sus adlá-

${ }^{2}$ Durante el período de Perón se intentó, incluso, construir aviones cazas a reacción. Se estableció un centro de investigaciones nucleares en Bariloche con la intención de producir la bomba atómica. Para mayores informaciones acerca de la política seguida por Argentina en materia nuclear ver: Jorge A. Sábato; "Energía atómica en Argentina" en la revista Estudios Internacionales, Octubre-Diciembre 1968, Santiago de Chile, pp. $33^{2-357}$.

${ }^{3}$ Este fue el grito con el cual las masas peronistas quemaron el Jockey Club de Buenos Aires, centro de reunión de las clases altas. 
teres se enriquecieron rápidamente gracias a la apropiación de los fondos fiscales. En muchos casos, posiblemente por un complejo "machista", su vida privada se caracterizó por excesos sexuales. Sin embargo, ésta no fue una regla aplicable a todos los casos. Odría, por ejemplo, no puede compararse con Pérez Giménez, Perón o Trujillo, en lo relativo a extralimitaciones sexuales.

Los origenes sociales de la totalidad de estos dictadores fueron modestos. En su mayoría provinieron de la clase media baja.

En materia política, no abjuraron del respeto formal a la democracia. Trataron de legitimizar su poder, en base a elecciones generalmente espúreas. En varios casos, reformaron las Constituciones y crearon partidos políticos de masas, obviamente oficialistas. La oposición fue reprimida.

Los principales dictadores dentro de esta corriente son: Getulio Vargas, en Brasil; Juan Domingo Perón, en Argentina; Rafael Leonidas Trujillo, en República Dominicana; Marcos Pérez Giménez, en Venezuela; Manuel Odría, en Perú; Anastasio, "Tacho" Somoza, en Nicaragua; Fulgencio Batista, en Cuba y Gustavo Rojas Pinilla, en Colombia. El General Stroessner, en Paraguay, es el único dictador populista que aún conserva el poder.

En resumen: los grupos que apoyaban al dictador, en la mayoría de los casos, eran los militares, los inversionistas extranjeros, la clase obrera organizada en sindicatos oficiales y el lumpenproletariat.

La oligarquía agraria mantuvo una actitud equívoca. En muchos casos, pese a su antipatia por la carencia de refinamiento de los caudillos populistas, los apoyó, debido a que sus intereses no fueron tocados. En Argentina, durante Perón, y en Brasil con Vargas, sin embargo, las clases altas mantuvieron una actitud hostil. Dentro de las Fuerzas Armadas la oposición se centró en la Marina ${ }^{4}$.

La oposición a la dictadura provino, en la totalidad de los casos, te los sectores medios: estudiantes, profesionales y partidos políticos que preconizaban una línea de centro izquierda. (En general, los movimientos social demócratas).

${ }^{4}$ La Marina fue elemento decisivo en el derrocamiento de Perón y de Pérez Giménez. El Almirante Rojas, jefe de la Armada Argentina, fue Vicepresidente de la República durante el Gobierno Provisional. Wolfgang Larrazábal, jefe de la Marina Venezolana, asumió la Presidencia Provisional de su pais, a la caida de Pérez Giménez. 
Alberto Sepúlveda / El militarismo desarrollista en América Latina

Los comunistas mantuvieron una actitud zigzagueante; pese a las declaraciones "anticomunistas" del régimen, normalmente el apelativo de "marxista" fue otorgado a los grupos democráticos reformistas.

La Iglesia mantuvo una actitud de apoyo. A mediados de la década del 50, cuando la mayoria de estos regímenes mostraron sintomas de franca descomposición, la Iglesia desató su oposición ${ }^{5}$.

EL MILLITARISMO DESARROLLISTA. $(1964 \ldots)$

Entre $195^{8}$-año de la caída de Batista- y $196_{4}$-año del golpe militar de Brasil que derrocó al Presidente Goulart - se produjo un periodo de transición ${ }^{6}$.

En la mayoría de los casos, las Fuerzas Armadas se retiraron a sus cuarteles y se produjo una profunda transformación, tanto en la organización como en el pensamiento de las Fuerzas Armadas.

El éxito de la guerrilla castrista y la posterior radicalización del régimen cubano obligaron, tanto a Estados Unidos como a los grupos de poder latinoamericanos, a revisar su actitud pasada.

Estados Unidos, bajo el liderato de Kennedy, se volcó a las tesis de los demócratas reformistas: social demócratas y demócrata cristianos. Temas como la industrialización acelerada, reformas sociales, integración económica, democratización y desarrollo, se convirtieron en las premisas de la nueva política, bautizada como Alianza para el Progreso. Su intención era derrotar al castrismo mediante el reemplazo de la sociedad agraria, con todas sus secuencias de feudalismo, miseria y' carencia de dinamismo, por una moderna sociedad industrial de tipo capitalista. Se trataba, en otras palabras, de repetir la receta del Plan Marshall,

${ }^{5}$ La oposición de la Iglesia comenzó contra Perón. Posteriormente, tuvo participación activa en la caída de Rojas Pinilla, Pérez Giménez y Batista. Sólo en el caso cubano se mostró partidaria de reformas sociales. En los otros casos, la oposición al dictador tuvo fundamentaciones principalmente politicas.

${ }^{6} \mathrm{Sin}$ embargo, en este período se produjeron golpes de Estado en varios paises, en algunos casos, contra gobiernos reformistas. El golpe militar peruano en 1962, y el que derrocó al Presidente Arosamena de Ecuador, dieron origen a Juntas que comenzaron a mostrar las caracteristicas de los militares desarrollistas. Para mayores detalles sobre este período ver Edwin Lieuwen Generales contra Presidentes en América Latina, Ed. Siglo $\mathrm{xx}$, Buenos Aires $196_{5}$. 
que tanto éxito tuvo en Europa, para eliminar el peligro comunista. Para "modernizar" América Latina era necesario, además de la ayuda económica, un vasto plan de reformas sociales.

La Iglesia, por su parte, aleccionada por la experiencia cubana, cambió su actitud pasiva y no crítica del statu quo por una vigorosa prédica en pro de las reformas sociales. El ala "liberal" de la Iglesia latinoamericana tendió a coincidir, en general, con el modelo de la Alianza. Sin embargo, se produjeron serias divisiones como consecuencia del nuevo enfoque. No solamente la jerarquía conservadora constituyó una oposición al grupo liberal reformista. También comenzó a nacer, a su izquierda, una corriente revolucionaria que, en varias ocasiones, ha tendido a coincidir con las tácticas castristas. Propicia, además, una sociedad de tipo socialista.

Las Fuerzas Armadas, por su parte, iniciaron o profundizaron, según el caso, dos tipos de transformaciones, una de tipo militar, la otra política.

Tradicionalmente, la función profesional de las Fuerzas Armadas había sido la defensa del país frente a una agresión exterior, normalmente de un vecino latinoamericano. En estas condiciones, se trataba de pequeñas unidades, dotadas de material y de conocimientos para una guerra clásica.

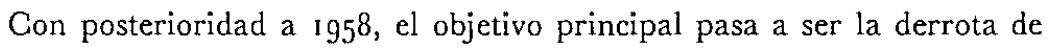
la subversión interna. El enemigo es el castrismo, que actúa a través de la guerrilla campesina y finca sus posibilidades de victoria en la correcta utilización de los problemas sociales.

La guerra de guerrillas encierra dos aspectos principales:

a. Militar. La guerrilla es una forma distinta de combatir, en la cual armamentos como tanques, aviones supersónicos y cruceros son inadecuados. El combate se da en pequeñas unidades, dotadas de armamento liviano, apoyadas por helicópteros o aviones de observación y en la cual los barcos rápidos y de pequeño calado son de utilidad, para las tropas antiguerrilleras, con el fin de impedir el aprovisionamiento del enemigo.

El soldado, a su vez debe estar entrenado para poder combatir en la selva o en las montañas. Las Unidades Especiales, como Rangers o Comandos, adquieren más importancia que el despliegue de gigantescos ejércitos. 
Alberto Sepúlveda / El militarismo desarrollista en América Latina

El combate debe darse por profesionales de alta calificación, en lưgar de masas de civiles armados, como es el caso de una guerra nacional ${ }^{7}$.

b. Político. La guerrilla sólo puede triunfar si cuenta con el respaldo de la masa campesina. Este apoyo es indispensable para obtener nuevos reclutas, conseguir alimentos, establecer líneas de aprovisionamiento seguras y contar con inteligencia adecuada acerca de los movimientos de las tropas gubernamentales.

La guerrilla no puede triunfar en base a ataques frontales, ya que es militarmente más débil que su enemigo. Su posibilidad de éxito radica exclusivamente en su capacidad para obtener un respaldo político creciente.

La pugna por la simpatía, o al menos la neutralidad, del campesinado, es en definitiva, el elemento de triunfo para el Gobierno o los insurrectos $^{8}$.

Esta situación obligó a las Fuerzas Armadas a dar una creciente importancia al estudio de los problemas del desarrollo, a la capacitación de sus oficiales en materias económico-sociales y a la divulgación de un pensamiento reformista, en sus filas.

No sólo la Acción Cívica Militar fue la consecuencia de este nuevo tipo de lucha. La incorporación de cursos de Sociología, Economía y Planificación, en las Escuelas Superiores de Guerra o en los Centros de Altos Estudios Militares, se vio reforzada por las necesidades de la lucha antisubversiva.

\section{CONSECUENCIAS DE LA LUCHA ANTIGUERRILLERA}

La etapa de la lucha contra la guerrilla produjo diversas consecuencias en las Fuerzas Armadas. Entre las más importantes debemos mencionar.

I. La reorganización militar. y la creación de unidades especiales que dejaron a las Fuerzas Armadas latinoamericanas en un excelente estado de preparación para reprimir una rebelión interna limitada:

La derrota de la guerrilla castrista dio al militar una seguridad creciente en su habilidad profesional para reprimir la subversión.

2. La capacitación en materias económico-sociales contrastó con la escasa sofisticación de los políticos tradicionales. En estas condiciones,

\footnotetext{
${ }^{7}$ Para mayores antecedentes ver John S. Pustay: Counterinsurgency Warfare, The Free Press; New York 1965; pp. I 16-1 36 .

${ }^{8}$ Ibidem, pp. ${ }^{136-1} 5^{0}$.
} 
E S T U D I O S I N T E R N A C I O N A L E S

el miembro de las Fuerzas Armadas tiende a sentirse más educado que los civiles y debido a su mejor organización, espíritu de cuerpo y mayor eficiencia, estima que tiene mayor capacidad para asumir el Gobierno y encauzar el proceso de modernización ${ }^{9}$.

3. El énfasis en el armámento liviano acarré el abandono de la renovación de material clásico. En estas condiciones, al término del período de lucha contra la guerrilla, las Fuerzas Armadas latinoamericanas se encontraron relativamente bien abastecidas de material liviano pero desp̧rovistas de armamento clásico, como aviones, tanques, barcos pesados, o bien, dotadas de un armamento muy obsoleto ${ }^{10}$. Esta situación será analizada más adelante.

En estas condiciones, a contar de I 964 , un nuevo tipo de militar comenzó a incursionar en la política. En Argentina, Brasil, Bolivia y Perú toman el poder y expresan que se mantendrán por un largo período, hasta completar el proceso de "modernización" de la sociedad.

\section{CARACTERISTICAS DE LOS MILITARES DESARROLLISTAS}

Con el fín de clarificar nuestro análisis y tipificar estas dictaduras, en adelante llamaremos "desarrollista", a esta corriente militar.

Las dictaduras se caracterizan, en líneas generales, por lo siguiente:

I Las Fuerzas Armadas como institución son las que toman el Gobierno. El Presidente de la República no es un caudillo personalista sino sólo el exponente del pensamiento y actitudes de las Fuerzas Armadas. Son las instituciones militares las que toman a su cargo la tarea de gobernar. En caso de renuncia o fallecimiento del Presidente, son ellas las que designan a su sucesor. Como un ejemplo puede citarse el caso brasileño donde, a contar de 1964 , se han producido tres casos de sucesión pacífica de un Jefe de Estado.

En estas condiciones, este tipo de dictaduras aparece con mayor estabilidad que en el caso de los populistas, ya que asegura un mecanismo de sucesión. Tiene la desventaja, sin embargo, de que al ser la institución armada la responsable de la política gubernamental se encuentra, como cuerpo, en una situación de menor flexibilidad que en el pa-

"Ver Francisco Arias Pellerano: "La participación política de las Fuerzas Armadas"; revista Estrategia, julio-agosto 1969 ; Buenos Aires, pp. 29-37.

${ }^{10}$ Ver David Wood: "Armed Forces in Central and South America", Adelphi Papers $\mathrm{N}^{\circ} 34$; Institute for Strategic Studies; Londres 1967 . 
Alberto Sepülveda / El militarismo desarrollista en América Latina

sado. Antiguamente, cuando la oposición civil era demasiado poderosa, las Fuerzas Armadas daban un contragolpe, deponían al dictador y asumía el poder un Gobierno Provisional que convocaba a elecciones. Esto sucedió en Argentina con Perón, en Colombia con Rojas Pinilla y en Venezuela con Pérez Giménez.

El contragolpe tenía la virtud de que las Fuerzas Armadas, como tales, podian capear el temporal y salvar su existencia como institución frente a una revolución triunfante. Sólo un grupo de oficiales era sancionado pero el resto aparecía en una actitud "civilista" y como uno de los factores del triunfo de la oposición.

En la actualidad, el grado de participación de la institución armada como tal, es tan marcada que la salida tradicional contará con serias dificultades y el grado de encono de los civiles será, posiblemente, mayor.

2. El nuevo oficial es de mayor sofisticación y tiende a recibir con agrado el asesoramiento de los tecnócratas. Las nuevas dictaduras, en los lugares donde han tomado el poder, han dado importancia al asesoramiento técnico $y$, de hecho, se han convertido en los intérpretes de la tecnocracia.

Sus Administraciones tienden a ser más eficientes y cuentan con mejores equipos técnicos que la de sus predecesores civiles.

3.El grado de honestidad, tanto pública como privada, del nuevo tipo de militar, es considerable. En algunos casos, como en Argentina, han llegado a asumir actitudes que rayan en el moralismo de la época victoriana.

4. Mejores relaciones con las Fuerzas Armadas de otros países de América Latina. En el pasado, el deber de las Fuerzas Armadas consistia en la prevención de invasiones de un país vecino.

Las relaciones entre los distintos grupos armados latinoamericanos se caracterizaban por la desconfianza.

En la actualidad, gracias, en parte, a la colaboración antiguerrillera y a la existencia de una mentalidad política similar, se da un grado de colaboración estrecha entre los gobernantes de esta corriente. Un ejemplo, en este sentido, ha sido la ayuda diplomática prestada al Gobierno de Bolivia y antes al del Perú, por sus congéneres uniformados ${ }^{11}$.

"Ver Henri Faure: "Reformisme civil et reformisme militaire au Perou"; Revista Politique Etrangere; $\mathrm{N}^{\circ}{ }_{3}, 196 \mathrm{~g}$, Paris, pp. 349-372. 
La mayor sofisticación, de este grupo, en materia internacional les permite tomar una actitud menos simplista frente a la Guerra Fría $y$ asumir una actitud de mayor independencia en relación con Estados Unidos. En el hecho, las relaciones con Europa y el bloque socialista tienden a aumentar ${ }^{12}$. Frente a la integración latinoamericana han asumido una actitud favorable, aunque con ciertas reservas ${ }^{13}$. Puede citarse como ejemplo, que fue la iniciativa del Gobierno de Brasil la que originó la reunión de CECLA ${ }^{14}$ y la politica seguida por Perú y Bolivia frente al Mercado Andino ${ }^{15}$.

5. El objetivo común de estas dictaduras, es la obtención del desarrollo económico. Es interesante analizar con más detalle el modelo de sociedad al cual aspiran.

En general, se trata de una sociedad de tipo capitalista moderno. La palabra "modernización"16 aparece reiteradas veces en las proclamas $y$ discursos de los gobernantes desarrollistas ${ }^{17}$. Su intención es la de crear una industria pesada que asegure una expansión económica y la elevación del poderío nacional y, por ende, del nivel de vida de la población ${ }^{18}$.

${ }^{12}$ Ver James Petras y Nelson Rimensnyder: "What is happening in Peru?": Revista Monthly Review; febrero 1970; New York, p. 28. También, Juan Velasco Alvarado: "Mensaje a la Nación", en Estrategia, op. cit., pp. 8 I-82.

${ }^{13}$ Velasco, Ibidem, p. 81.

${ }^{14}$ Ver José de Magalhaes Pinto: "Conferencia pronunciada en la Escuela Superior de Guerra el 3 de junio de I 969 ", en Estrategia, op. cit., p. 185.

${ }^{15}$ Ver mi artículo "El Mercado Andino" en la revista Documentos Internacionales $N^{\circ}{ }_{14}$, Santiago, pp. 9-28.

${ }^{16} \mathrm{El}$ término "modernización" es usualmente empleado por los cientistas políticos norteamericanos. En general, ponén como modelo de modernización política y económica a los sistemas vigentes en el mundo Occidental. En la práctica, de acuerdo con esta teoría, un pais se moderniza en la medida que se acerca a los esquemas políticos y económicos del neocapitalismo. Para conocer más en detalle esta línea de análisis ver David E. Apter: The Politics of Modernization, The University of Chicago Press, Chicago, ig65.

${ }^{17}$ Ver por ejemplo el libro de Mario Horacio Orsolini, Ejército Argentino y Crecimiento Nacional, Ed. Arayú, Buenos Aires, 1965 .

${ }^{18}$ Ibidem, pp. 227 y 228 también Estrategia, op. cit., los artículos de Eduardo Juan Uriburu "El Plan Europa. El Ejército y su contribución a la estrategia del desarrollo" y Enrique Gilardi Novaro "El sector agropecuario, su tecnificación y las Fuerzas Armadas". 
En estas condiciones, no son tantas las diferencias de enfoque entre las políticas del Gobierno del Perú y de Argentina. Lo distinto es el grado de desarrollo y la estratificación social de ambos países.

En el caso del Perú, la industria es incipiente, hay grandes diferencias de ingreso e, incluso, de cultura entre las tres regiones del país: sierra, costa y selva.

En la sierra la población indígena vive al margen de la economía de mercado, no habla, en su mayoría, español, es explotada por los latifundistas y no se siente integrada a la nacionalidad peruana.

La costa es más urbanizada, la agricultura usa técnicas modernas y opera en base a la plantación o hacienda, con gran inversión de capital. El peón agrícola semeja más un obrero industrial que un campesino típico ${ }^{19}$.

La selva está casi despoblada y en etapa de colonización. Su incidencia en la vida nacional es pequeña.

En el Perú el proceso de industrialización contaba con la oposición de los grupos tradicionales de poder: exportadores, importadores y latifundistas. Estos sectores se habían opuesto a las intenciones del Presidente Belaúnde de aumentar los derechos aduaneros como un medio de proteger la naciente industria nacional.

En el caso del Perú una política de "modernización" o de establecimiento de un sistema capitalista moderno, implica la adopción de reformas que liquiden el poderío de la antigua estructura agrario-exportadora-importadora.

La política de reformas sociales del gobierno peruano tiende a crear las condiciones para la aparición de un empresariado capitalista nacional. En la práctica, este sector, conjuntamente con los campesinos de la sierra, es el gran favorecido por la Revolución Peruana ${ }^{20}$. En cierta medida, está cumpliendo el mismo papel histórico que le cupo al peronismo en Argentina: La integración de los sectores marginales y la creación de un empresariado nacional.

En lo relativo al capital extranjero, la actitud de Velasco tiende a prestarse a equívocos.

${ }^{19}$ Ver Antonio Garcia: "Proceso y frustración de las reformas agrarias en América Latina" en Estudios Internacionales, octubre 1967, marzo 1968, p. 359.

${ }^{20}$ Petras, op. cit., pp. ${ }^{15-16 .}$ 
La nacionalización de la International Petroleum Company (IPC) no tiene un fundamento ideológico. Las actividades de IPC han constituido una ofensa al orgullo nacional peruano. Su fundamentación legal era tan turbia y sus operaciones económicas tan sospechosas que su nacionalización puede mirarse más como una reafirmación de la autoridad del Gobierno, que un caso de repulsión al inversionista privado ${ }^{21}$. La nacionalización constituyó, además, una excelente maniobra política para obtener respaldo popular ${ }^{22}$.

La política del Gobierno Revolucionario tiende a incrementar las inversiones foráneas, en lugar de disminuírlas. Las negociaciones en torno a la explotación de los minerales de cobre y los constantes anuncios en la prensa norteamericana tienden a dejar esa impresión.

Es así que en una inserción en el New York Times, financiada por el Gobierno y bajo el título "Tenemos fe en el futuro del Perú', el general Juan Velasco Alvarado expresa:

No hay conflicto entre las metas de la Revolución y los justos requerimientos de los inversores. El proceso revolucionario busca un cambio en las estructuras para establecer un ambiente de justicia social, donde las actividades privadas puedan desarrollarse, no desaparecer o limitarse.

La constante preocupación del Gobierno Revolucionario de las Fuerzas Armadas es garantizar, en el pais, las condiciones necesarias para el normal desarrollo de'las actividades económicas. Se ha reiterado, en varias oportunidades, que, en este contexto, el Gobierno del Perú garantizará todas las facilidades que cualquier inversor, sea nacional o extranjero, pueda requerir como legitimo incentivo para su actividad.

Una nueva realidad en el Perú ofrece un amplio campo de interés para los empresarios. Ellos tendrán siempre el estímulo de un Gobierno que entienda la absoluta importancia de la actividad privada para el desarrollo integral del pais ${ }^{23}$.

En el caso de Argentina, se trata de un país integrado nacionalmente, donde el proceso de incorporación del lumpenproletariat o "marginales" se realizó en el Gobierno de Perón. Argentina posee una poderosa industria, elevados índices de alfabetismo, una renta per cápita de las

\footnotetext{
${ }^{21}$ Ibidem p. 21.

${ }^{22}$ Ibidem p. 21.

${ }^{23}$ Ver The New York Times, 26 de enero, p. 74 .
} 
más elevadas de América Latina, una organización sindical sólida $y$ no existen marcadas diferencias sociales. Argentina; es más que un país subdesarrollado. Podría ser calificado como una sociedad capitalista desarrollada que ha permanecido estancada por 20 años.

El Gobierno de Ongania trató de crear las condiciones que permitieran dar un nuevo impulso a la actividad económica ${ }^{24}$. Por ello, se dió más énfasis a la "modernización" que a la "reforma" de las estructuras. Argentina, sin embargo, ha comenzado a sufrir el mismo proceso de Europa Occidental por el cual el capital foráneo, especialmente estadounidense, paulatinamente asume la propiedad o el control de centros importantes de la industria nacional. Esta situación chocó con el nacionalismo del equipo gobernante.

En Argentina, sin embargo, la situación politica posterior a Perón ha impedido la integración en los marcos del Estado capitalista de la clase obrera. Este vacio, o esta pugna entre grupos medios -interpretados políticamente por el radicalismo- y la clase obrera -expresada en el peronismo- ha contribuido a mantener la inestabilidad politica $y$ las frecuentes asonadas de las Fuerzas Armadas.

En Perú y Argentina, la oficialidad joven tiende a ser más izquierdista que sus mayores ${ }^{25}$. En el caso del Perú, puede llevar a una radicalización del proceso. En el de Argentina, paradojalmente, a la consolidación del capitalismo en base a la reconciliación entre militares y sindicatos, que permita la integración de la clase obrera al sistema.

6. En ciertos casos, la fundamentación del desarrollo es hecha en base a. consideraciones de "seguridad nacional". De acuerdo con esta teoría, para que un país tenga Fuerzas Armadas poderosas, que puedan proteger la soberanía nacional, es indispensable la existencia de una economía industrial moderna, capaz de sostener los gastos militares y de fabricar el armamento necesario ${ }^{26}$.

\footnotetext{
${ }^{24}$ Ver Orsolini, op. cit., p. 227.

${ }^{25}$ El golpe militar en Perú implicó la aparición de una línea "peruana" dentro de las FF.AA, argentinas. Esta línea pareciera ser fuerte en los sectores jóvenes. De hecho han presionado por mayores reformas sociales.

${ }^{26}$ Ver Umberto Peregrino: "O pensamento da Escola Superior de Guerra", en la revista Cadernos Brasileiros, $\mathrm{N}^{\circ} 34$, pp. 29-38.
} 
E S T U D I O S I N T E R N A G I O N A L E S

Desarrollo y seguridad nacional son aspectos de una misma problemática. Sin seguridad el desarrollo se ve amenazado por las ambiciones de otras potencias. Sin desarrollo, el grado de seguridad que pueden proporcionar las Fuerzas Armadas es limitado debido a la modestia de recursos económicos". La fundamentación ideológica de la "modernización", entonces, está concebida en términos bélicos. Esta mentalidad belicista contrasta con los hechos. En la práctica, se gasta menos en armamentos que en el pasado y las relaciones con las "potencias agresivas", es decir los vecinos geográficos, mejoran en lugar de empeorar ${ }^{28}$.

Esta mentalidad favorece la investigación tecnológica en materia militar. Brasil y Argentina están fabricando cohetes de medio alcance y realizan una seria investigación núclear ${ }^{29}$.

El mayor problema de esta ideología es que constituye una barrera para el eventual traspaso del poder a los civiles, menos preocupados por los problemas de seguridad nacional.

\section{LA AYUDA MILITAR NORTEAMERICANA Y SUS EFECTOS EN LAS FUERZAS ARMADAS DE AMERICA LATINA}

En general, podemos distinguir tres etapas en la ayuda militar prestada por Estados Unidos a la América Latina, desde el fin de la Segunda Guerra Mundial.

\section{Ayuda militar clásica (1945-1960)}

Durante la Segunda Guerra Mundial, la constatación de la debilidad de las Fuerzas Armadas latinoamericanas para resistir un eventual ataque del Eje creó serias preocupaciones al Alto Mando estadounidense.

La posibilidad de que Rommel cruzara el Atlántico desde Africa, se demostró como una operación técnicamente factible. La costa brasileña está situada a una distancia relativamente cercana de Africa Occidental y tanto divisiones aerotransportadas como cuerpos de Ejército desembarcados por una flota naval, podían invadir al Brasil.

\footnotetext{
${ }^{27}$ Ibídem, p. 3 I.

${ }^{28}$ Ver Joseph E. Loltus Latin American Defense Expenditures, 1938-1965, The Rand Corporation, Santa Mónica, California, 1968, pp. 9-16.

${ }^{29}$ Para mayores informaciones ver Sábato, op. cit., pp. 345-357.
} 
Alberto Sepúlveda / El militarismo desarrollista en América Latina

Las flotas alemana y japonesa, especialmente sus barcos corsarios y submarinos, podrían utilizar el amplio litoral latinoamericano para abastecerse y eludir la persecución de las flotas aliadas ${ }^{30}$.

Por estas razones, Estados Unidos contribuyó con una considerable ayuda militar a los gobiernos latinoamericanos y obtuvo bases en las Islas Galápagos y en Natal.

Por parte de América Latina, sólo un escuadrón aéreo mexicano y una división brasileña participaron en los combates contra el Eje. La Marina del Brasil colaboró con los Aliados en la protección de convoyes en la zona del Atlántico Sur.

Al término de la guerra, la Unión Soviética reemplazó al Eje como el principal adversario de Estados Unidos.

El Gobierno de Estados Unidos contribuyó, èn gran escala, a incrementar el poderío de las Fuerzas Armadas latinoamericanas con el fin de capacitarlas, en cierta medida, para resistir una eventual invasión soviética ${ }^{31}$.

Durante la década del 50, Estados Unidos presionó por la celebración de pactos bilaterales de ayuda mutua con los países latinoamericanos, pese a la existencia de un acuerdo colectivo de seguridad militar: El Tratado Interamericano de Asistencia Recíproca, firmado en Río de Janeiro, en I 947 .

El objeto de la ayuda militar, pues, en el período que analizamos, fue la capacitación de las Fuerzas Armadas latinoamericanas para el combate contra otra organización militar profesional: El Ejército Rojo de la URSS.

América Latina recibió naves pesadas, como cruceros y destroyers, tanques y aviación de guerra ${ }^{32}$. Otro de los objetivos de la ayuda militar. estadounidense era uniformar el adiestramiento y el tipo de armamentos de la FF.AA. latinoamericanas, con el fin de poder utilizarlas eficientemente como auxiliares en caso de una nueva guerra mundial.

${ }^{30}$ De hecho en el Sur de Chile varios submarinos alemanes fueron abastecidos durante las Dos Guerras Mundiales.

${ }^{31}$ Ver Harold A. Hovey, United States Military Assistance: A study of Policies and Practices; Ed. Frederick A. Praeger, New York, $1965, \mathrm{pp} .53^{-56}$.

${ }^{32} \mathrm{Ibidem}, \mathrm{p} .55$. 


\section{Desarrollo de las unidade's anliguerrilleras (10660-(5,5)}

El triunfo de la guerrilla castrista y la diseminación de los métodos irregulares de combate, por el continente, llevó al Gobierno de Kennedy al convencimiento acerca de la inefectividad de las Fuerzas Armadas latinoamericanas para lidiar con la subversión interna.

Asimismo, el desarrollo del potencial nuclear $y$ coheteril de la Unión Soviética, la superioridad naval de Estados Unidos y la inexistencia de un poderoso Estado, continental comunista, en América Latina, (Cuba es una isla) capaz de invadir militarmente a algún país, corntribuyeron a desestimar la posibilidad de una invasión comunista. Por ende, el papel clásico de las Fuerzas Armadas latinoamericanas quedó obsoleto.

Kennedy dio especial énfasis a la lucha antiguerrillera. En otras páginas hemos analizado los efectos políticos y estratégicos de esta medida. Ahora estudiaremos lo acaecido con los armamentos.

Como es de suponer, la asistencia militar estadounidense se centró en material liviano. Solamente por un tiempo se siguieron proporcionando destructores y submarinos a las Marinas latinoamericanas. Posteriormente, este tipo de naves fueron reemplazadas por embarcaciones rápidas ${ }^{33}$.

Como, al mismo tiempo, los gasto militares latinoamericanos sufrieron una considerable disminución ${ }^{34}$ no se reemplazó, con fondos propios el material pesado. Como consecuencia, la mayoría del equipo bélico latinoamericano está integrado por piezas provenientes de la Segunda Guerra Mundial. Solamente contados aviones son del período del $5^{\circ}$ (primera generación de aviones jet), los tanques son Sherman, de la segunda guerra. En síntesis, las Fuerzas Armadas latinoamericanas, cuentan con material antiguo y obsoleto de dudosa utilidad en caso de un conflicto, si es que puede usarse ${ }^{35}$.

\section{Retiro de Estados Unidos (7965...)}

La guerra de Vietnam concentró los esfuerzos de Estados Unidos. Las derrotas de las guerrillas castristas hicieron desaparecer el temor por la

\footnotetext{
${ }^{33}$ Ibidem, pp. 59-60.

${ }^{34}$ Ver Loftus, op. cit., pp. I 1-12.

${ }^{35}$ Ver Wood, op. cit., pp. 5-10.
} 
seguridad latinoamericana. Al mismo tiempo, la crítica de los senadores opositores al Pentágono, por el manejo de la guerra de Vietnam, condujo a una presión permanente en torno a la reducción de la ayuda militar.

Las principales críticas hacia la colaboración militar norteamericana con los ejércitos latinoamericanos, de parte de los senadores pacifistas ("palomas") tales como Fulbright o MacCarthy, se centraron en el número de golpes militares en América Latina. Estados Unidos, con su ayuda militar, en lugar de propender a la democratización del continente, estaria contribuyendo a la propagación de las dictaduras. En segundo lugar, la alianza de los militares con las fuerzas del statu quo estaría haciendo peligrar el programa de reformas sociales de la Alianza ${ }^{36}$.

En la actualidad, la tendencia es hacia una reducción casi completa de la ayuda militar estadounidense ${ }^{37}$.

Un estudio de la Rand Corporation, después de un análisis detallado de varios golpes militares latinoamericanos llegó a la conclusión de que no podía achacarse a la ayuda estadounidense la intervención en política de las Fuerzas Armadas de la región. Señaló que esta situación existía con anterioridad a la ayuda y que en algunos casos, como el de Argentina, el golpe se produjo cuando el momento de ayuda era casi inexistente ${ }^{38}$.

En el caso de los militares que siguieron estudios en Estados Unidos o en Panamá, pareciera que tampoco hay una influencia mayor. Dos de los más destacados altos jefes militares latinoamericanos que cursaron en Estados Unidos son el Presidente Velasco, del Perú y su Ministro de Relaciones, General Mercado ${ }^{39}$.

${ }^{36} \mathrm{Ver}$ "United States military policies and programs in Latin America, Hearings, 1969", U.S. Congress, Senate, Subcommitee on Western Hemisferic Affairs, pp. 9-27.

${ }^{37}$ Ibídem, pp. $61-65,80-81$.

${ }^{38}$ Ver Charles Wolf The Political Effects of Military Programs; Some indications from Latin America, the Rand Corporation, Santa Monica, California, junio Ig63.

${ }^{39}$ Los altos jefes latinoamericanos que estudiaron en Estados Unidos son: General Aurelio de Lyra Tavares, Ministro de Guerra del Brasil, General Fidel Sánchez Hernández, Presidente de El Salvador; Teniente Anastasio Somoza Debayle, Presidente de Nicaragua, Brigadier Juan Velasco Alvarado, Presidente del Perú y Brigadier General Edgardo Mercado Jarrín, Ministro de Relaciones Exterinres del Perú. Esta información fue proporcionada al Subcomité de Asuntos del Hemisferio Occidental, del Senado Norteamericano, por Charles A. Meyer, Secretario Asistente de Estado para los Asuntos Interamericanos, en la sesión del 8 de julio de 1969 . Ver "United States military policies...", op. cit., p. 82 . 
Se puede señalar que si bien pareciera no haber una relación directa entre golpe militar y ayuda norteamericana, tampoco es posible desconocer otros aspectos de influencia.

La asistencia en materia de armamentos y entrenamiento ha permitido a las Fuerzas Armadas latinoamericanas el acceso a medios bélicos y sistemas de adiestramiento que les habría sido imposible alcanzar con los meros recursos nacionales.

Es así, entonces, que el instrumental de violencia puesto a disposición de un militar político es considerablemente superior gracias a la ayuda norteamericana. Se puede señalar que, en algunos casos —como el de Bolivia, por ejemplo-, el potencial bélico de algunos grupos armados de la población (como los mineros) habría bastado para impedir un golpe militar.

Cabe recalcar, además, que si bien, en la mayoría de los casos, no hay una influencia política directa, por parte de Estados Unidos, si la hay en materia ideológica. Las doctrinas de seguridad nacional que, en muchos casos, constituye la filosofía política de los gobiernos militares, ha sido desarrollada fundamentalmente por Estados Unidos ${ }^{40}$.

En general, el modelo de sociedad a la cual aspiran los dictadores desarrollistas está basado en el esquema capitalista estadounidense y en sus valores ideológicos. Así, al menos, parece desprenderse de los discursos y proclamas de las principales figuras de los gobiernos militares. La empresa privada constituye el motor de la actividad económica, el capital extranjero es considerado vital para el desarrollo y la "democracia" es el fundamento político de las dictaduras militares". En síntesis un modelo clásico de los valores y esquemas que fundamentan el neo-capitalismo.

\section{¿SON SOLIDAS LAS DICTADURAS MILITARES DESARROLLISTAS?}

En la actualidad, Ios militares que han seguido cursos en el extranjero o se han graduado en las escuelas superiores de guerra o centros de altos

${ }^{40}$ Ver Peregrino, op. cit., p. 30.

${ }^{41}$ Ver José de Magalhaes Pinto "Conferencia...", op. cil., pp. 180-181; tambièn, Aurelio de Lyra Tavares "El Ejército Brasileño y la actual coyuntura nacionala" en Estrategia, op. cit., pp. $4^{2-49}$. 
Alberto Sepúlueda / El militarismo desarrollista en América Latina

estudios militares lucen una mayor sofisticación que los políticos tradicionales de América Latina ${ }^{42}$.

Al mismo tiempo, la carencia de sólidas organizaciones políticas y sociales parecen asegurar a las Fuerzas Armadas una superioridad aparentemente sin contrapeso ${ }^{43}$.

El éxito en la represión de los estallidos guerrilleros pareciera contribuir a aumentar la confianza de los grupos castrenses en su capacidad para reprimir cualquier intento para desalojarlos del poder.

Por último, la unidad de las Fuerzas Armadas y la desaparición, al menos aparente, de las rivalidades entre las diversas ramas (Marina, Ejército y Fuerza Aérea) y la ausencia de pequeños grupos de oficiales que conspiren contra sus superiores, pareciera reforzar la presunción en torno a la solidez y estabilidad de las dictaduras desarrollistas.

Los elementos señalados en los párrafos anteriores, hacen presumir a muchos que los militares desarrollistas latinoamericanos son la única fuerza capaz de modernizar la región y de reformar sus arcaicas estructuras. De acuerdo con esta corriente de análisis, nos encontraríamos ante oficiales capaces de emular el papel histórico de Mustafá Kemal Ataturk, en Turquía y de Gamal A. Nasser, en Egipto.

Los planteamientos anteriores requieren de un análisis más detallado.

\section{La comparación con Ataturk y Nasser.}

Mustafá Kemal Ataturk fue un oficial turco que, a la caída del Imperio Otomano, con posterioridad a la Primera Guerra Mundial, y con ocasión de la invasión de su patria por las tropas aliadas, especialmente las griegas, se levantó en armas. Expulsó a los invasores y. obligó a las potencias aliadas a reformar el duro Tratado de Paz con su país ${ }^{44}$. Ataturk, que significa "Padre de los turcos", reemplazó el multinacional Imperio Oto-

${ }^{42}$ Ver "The New Military" en la revista Newsweek, 5 de enero de 1970, pp. 26, 27 y 28.

${ }^{43}$ Ibidem, pp. 26-28.

${ }^{44}$ Para mayores antecedentes ver Roderic H. Davison: Turkish Diplomacy from $M u-$ dros to Lausanne en el libro de Gordon A. Craig y Felix Gilbert, "The Diplomats 19191939", vol. i; Ed. Atheneum New York, 1967, pp. 172-210. 
E S T U D I OS I N T ER N A C I ONALE S

mano por el Estado Nacional Turco y se dedicó a la ardua tarea de modernizar su patria para sacarla del atraso ${ }^{45}$.

Ataturk, si bien estaba respaldado por las Fuerzas Armadas, era reconocido como el héroe nacional y caudillo de Turquía, por la masa popular. Esta situación le permitió ejercer un control indiscutido sobre el Ejército ${ }^{46}$.

El objetivo de Mustafá Kemal fue la creación de una democracia occidental y de una moderna economía industrial. En tal sentido, se preocupó de crear una organización política de masas que respaldara su gobierno y de cambiar las costumbres tradicionales de su pueblo.

Sus afanes democráticos lo llevaron al extremo de propiciar la creación de un partido de oposición a su gobierno.

El constante debilitamiento del otrora poderoso Imperio Otomano, su atraso frente a Europa y el peligro de desaparición de la comunidad nacional turca — como casi sucedió a fines de la Primera Guerra Mundial - fueron elementos que contribuyeron a crear un clima político adecuado para el experimento de Ataturk.

La "modernización" y la disciplina que impuso el régimen del carismático caudillo adoptaron el carácter de elementos indispensables para la supervivencia del Estado turco.

Ataturk trató de "desmilitarizar" su gobierno. Se rodeó de asesores civiles y propició la separación de las Fuerzas Armadas de las actividades políticas ${ }^{47}$.

Su régimen, mal puede calificarse de "militarismo progresista". Fue más la labor de un caudillo, de rara habilidad política, que sirvió en el Ejército.

En el caso de Nasser encontramos algunos elementos parecidos.

Fue la humillante derrota sufrida frente a los judios, en 1948, la que constituyó el mejor impulso para la toma del poder por parte de los jóvenes militares egipcios ${ }^{48}$.

La constatación de la debilidad nacional y de la corrupción e inefi-

${ }^{45}$ Ver Samuel P. Huntington: Political Order in Changing Societies; Yale University Press, New Haven, ig68, pp. 70, 221, 241, 261, 269, 256-58.

${ }^{46}$ Ibidem, pp. 256-58.

${ }^{47}$ Ibidem, pp. 347-357.

${ }^{48}$ Ibidem, pp. 205, 246, 247. Ver también Nadav Safran: From War to War: The ArabIsraeli confrontation 1948-1967, Ed. Pegasus, New York, 1969, pp. 288-36. 
Alberto Sepúlveda / El militarismo desarrollista en América Latina

ciencia del régimen de Farouk fueron los elementos principales que motivaron la actuación política de Nasser.

El caudillo árabe demostró ser capaz de crear organizaciones de masas y de apoyarse en otros grupos civiles como un medio de neutralizar el poderío del Ejército. Al término de la Guerra de los Seis Días consiguió realizar una purga en las Fuerzas Armadas sin mayor oposición, dramatizando así su control político.

El conflicto con Israel hà servido para reforzar al régimen en el po$\operatorname{der}^{49}$.

En los dos casos, el proceso de reformas sociales se ha debido más a la obra personal de políticos carismáticos, salidos de las filas del Ejército, que a un modelo de modernización llevado a cabo por las instituciones armadas.

En la práctica, el prestigio del caudillo le permitió consolidar su poder y someter a las Fuerzas Armadas. a su control. En esta materia, encontramos un caso similar en España. Franco, merced a su habilidad política y a su prestigio, ha podido someter a las Fuerzas Armadas.

En la práctica, no existen antecedentes sobre casos en que las instituciones militares, como tales, hayan sido capaces, no sólo de modernizar, sino de mantener el poder por un largo tiempo.

En América Latina faltan algunos elementos claves que se dieron en Turquía y Egipto: Un héroe nacional, capaz de asumir el papel de "Padre de la Patria", y la existencia de una larga humillación nacional y de una constante amenaza para la seguridad o existencia del Estado. Este clima psicologico más el atractivo de la personalidad del lider son los elementos que permitieron la consolidación de Ataturk y Nasser.

Posiblemente, en el único país de América Latina donde se encuentre una situación parecida a la reseñada es Cuba, amenazada (o con psicosis de amenaza) por una eventual invasión norteamericana y con Fidel Castro asumiendo el papel del caudillo nacional, con ribetes de heroísmo.

\section{El grado de sofisticación de los militares desarrollistas.}

Es indudable que, en nuestros días, los oficiales de las Fuerzas Armadas tienen un conocimiento mayor sobre los problemas nacionales y las

${ }^{49}$ Safran, op. cit., pp. $83-88$. 
E S T U D I OS IN T ER N A C I O N A L E S

fórmulas para resolverlos, que en el pasado. En algunos países, son más sofisticados que los políticos civiles tradicionales.

Esta situación de superioridad intelectual sobre los civiles es transitoria. En la actualidad, miles de jóvenes latinoamericanos se encuentran cursando estudios en el exterior. Sólo el Perú tiene cerca de 5.000 estudiantes en el extranjero ${ }^{50}$.

La educación ha sido uno de los sectores de mayor desarrollo durante la década del 6o. En materia universitaria ha habido un incremento espectacular en la calidad, técnicas pedagógicas y número de educan$\operatorname{dos}^{51}$.

Las ciencias sociales han tenido gran expansión. Un creciente número de Institutos están produciendo graduados capaces de proveer técnicas más sofisticadas para analizar los problemas del subdesarrollo.

En América Latina estamos presenciando un proceso de explosión educacional.

La ventaja inicial de los uniformados, en relación con su contraparte civil, es cada día menor, si no ha desaparecido ya.

Los militares desarrollistas están cumpliendo el papel de intérpretes políticos de la tecnocracia latinoamericana. Cabe preguntarse, sin embargo, si esta situación se mantendrá por un largo período. En la medida que el número de tecnócratas aumente es posible que aspiren a dirigir el país directamente, sin la participación castrense. Es de esperar, al mismo tiempo, que varios de los más sofisticados estudiantes o jóvenes profesionales de hoy, asumirán labores políticas en el fururo, proporcionando líderes con una educación muy superior a la de los militares, al menos, en los problemas de gobierno.

La posibilidad de una tecnocracia militar que oriente a los civiles es una alternativa de difícil aplicación. No sólo porque para su realiza-

\footnotetext{
${ }^{50}$ De acuerdo con los cálculos de las Naciones Unidas en 1969 habria más de 120.000 estudiantes en el exterior. El alto costo de estos programas ha hecho que varios analistas recomienden una ayuda para mejorar las universidades de los paises subdesarrollados, en lugar de -seguir con estos gigantescos programas de becas. De los países de América Latina, Perú es el pais que tiene mayor número de alumnos en el exterior en proporción con la población universitaria. Los grupos más importantes están en Argentina, España y Estados Unidos.

${ }^{31}$ Ver Nelson A. Rockefeller The Rockefeller Report On the America's, Ed. Quadrangle, New York, 1970, pp. 106-115.
} 
ción habría que cerrar las Universidades para impedir el flujo de graduados civiles, sino porque el oficial debe escoger ante la alternativa de ser un experto en asuntos militares o un tecnócrata. El grado de desarrollo de las ciencias sociales y de la ciencia militar obliga a una especialización.

Es difícil que la tecnocracia soporte por un largo período el dominio militar. Incluso, en el caso de la España de Franco, los tecnócratas civiles del Opus Dei han desplazado de los asuntos de Gobierno a los militares.

En el caso de Thailandia, se ha llegado a un compromiso en el reparto del poder entre militares y burocracia.

En ambos casos ha sido la presencia de una autoridad superior a la de las Fuerzas Armadas y a los grupos tecnócratas la que ha permitido este proceso de acomodo. En el caso de España, por ejemplo, Franco juega el papel de árbitro entre las distintas facciones.

En el caso de las dictaduras desarrollistas la pretensión de las Fuerzas Armadas de asumir como tales el poder y de considerar al Presidente no como un caudillo, sino como un simple delegado, atenta contra este proceso de acomodo.

Sin embargo, la aparición de nuevos grupos en el Gobierno es un proceso natural, en especial cuando el país empieza a desarrollarse y surgen nuevos intereses. En estas condiciones, el experimento del militarismo desarrollista sólo puede conducir a dos alternativas: o a la aparición de un caudillo por encima de las facciones, que asuma el control de las Fuerzas Armadas y las "despolitice", gobernando con técnicos provenientes del sector civil y creando organizaciones de masas que respalden su gobierno o bien a la pérdida del poder, por su incapacidad para gobernar. Este problema se hará más agudo en la medida que la sociedad se desarrolle y se haga, por ende, más compleja.

En estos momentos, la tensión entre tecnócratas y militares aún no se ha demostrado y el poder de las Fuerzas Armadas aparece como incontrarrestable. Hay algunos elementos, sin embargo, que conviene analizar.

En la actualidad hay una alianza natural entre tecnócratas y militares, en especial en aquellos países menos desarrollados, como Perú y Bolivia.

La tecnocracia es débil y carece de un intérprete político que sea una 
alternativa a los militares. Además, civiles y uniformados coinciden en las metas a corto plazo: la necesidad de reformas que permitan industrializar el país y construir una sociedad moderna. El enemigo a derrotar son los grupos tradicionales y ciertos enclaves del capital extranjero. En el combate contra las fuerzas de la sociedad agraria ambas fuerzas confluyen. Sin embargo, en etapas posteriores es previsible el conflicto, en especial ante las alternativas de "desarrollo" o "seguridad nacional", es decir en la determinación de las inversiones. Es en estas condiciones que el choque de ideologías distintas se hará sentir y que el control del poder asumirá importancia.

\section{El problema del respaldo popular.}

Todo gobierno, aún el más totalitario, requiere de un grado importante de respaldo popular. Por ello, cualquier grupo que aspire a conservar el poder debe crear organizaciones de masas de tipo político $y$ social que le permitan influir en la población.

Crear organizaciones de masas implica, en cierta medida, restar poderío a las Fuerzas Armadas ya que pasan a ser uno de los grupos que respaldan el Gobierno y no el único. Normalmente, la creación de organizaciones de masas ha implicado algo más: el fin del poder político de las Fuerzas Armadas y su retiro a los cuarteles. Si bien el Presidente puede haber sido un oficial, es él quien asume el poder real y se convierte en árbitro entre las distintas facciones. Normalmente, este periodo ha coincidido con llamados para que las Fuerzas Armadas se dediquen, con exclusividad, a sus labores profesionales. Vale decir que se retiren de la política ${ }^{52}$.

Es aqui donde encontramos otro de los círculos viciosos del experimento de los soldados desarrollistas. Si no quieren perder el poder deberán crear organismos de masas. Y si los crean, lo perderán.

Pretender gobernar por la fuerza, sin un grado de respaldo de la población es algo históricamente imposible. En el caso de América Latina, además, el poderío de las Fuerzas Armadas es extraordinariamente limitado.

América Latina es la región del mundo que gasta menos en armamentos

${ }^{52}$ Huntington, op. cit., pp. 256-26o. 

después de Africa negra ${ }^{53}$. El armamento es obsoleto y en su mayoría se trata de material de la segunda guerra mundial. El número de hombres bajo las armas es escaso. Brasil, por ejemplo, que posee las Fuerzas Armadas más poderosas de América Latina, tiene cerca de 200.000 hombres armados, para controlar una población de cerca de go millones de habitantes ${ }^{54}$.

Argentina cuenta con 132.000 soldados para una población de cerca de 25 millones. En 1969, con ocasión del estallido de movimientos de protesta en Córdoba y Rosario, el Ejército se vió en serias dificultades para controlarlos. Se estimó que si al mismo tiempo hubiera estallado la protesta en Buenos Aires el Gobierno habría caído ${ }^{55}$.

Pero, además, habría que estimar cual es la real capacidad ofensiva de las Fuerzas Armadas. Los reclutas no son de segura lealtad para un régimen y habría que analizar cuál es la cantidad de hombres en labores administrativas o de apoyo. En el caso de las tropas norteamericanas en Vietnam, por ejemplo, sólo i de cada to soldados es tropa de combate.

Las perspectivas futuras hacen suponer que la relación numérica entre soldados y población disminuirá en lugar de aumentar. Los gastos militares serán aumentados, sobre todo, por la necesidad de renovación de material. Sin embargo, los altos costos del instrumental bélico moderno implicarán que, en definitiva, las Fuerzas Armadas latinoamericanas de 1975 serán proporcionalmente más débiles que las de 1945. Además, la explosión demográfica hace muy costoso pretender mantener Fuerzas Armadas que tengan la antigua. proporción, frente a la masa civil.

El Ministro de Ejército del Brasil, General Aurelio de Lyra Tavares, en una conferencia ante la Escuela de Guerra Naval de su país, expresó:

En el informe del Ministro está esbozado uno de los considerados grandes problemas del Ejército. Es el resultante del crecimiento demográfico, en relación con el desarrollo económico del país, que no permite que sea acompañado por un desarrollo acorde del Ejército.

${ }^{53}$ Loftus, op. cit., pp. 45-47,51-57.

${ }^{54}$ Ibidem, p. 87.

${ }^{55}$ Información proporcionada por dirigentes estudiantiles argentinos. De acuerdo con ellos en 1970 se trataría de perseguir estallidos de manifestaciones populares simultáneas en Rosario (Rosariazo), Córdoba (Cordobazo) y Buenos Aires (Porteñazo). 
...De acuerdo con la tasa de crecimiento del decenio $1950 / 1960$, Brasil alcanzará en 1976,114 millones de habitantes y un mínimo de 147 millones en 1986 . Esto significa que casi duplicará su población en los próximos veinte años. En tanto, el Ejército tenía en sus filas, en 1955 , el $0,27 \%$ de la población, en 1966 el $0,20 \%$ y si no fuere aumentado convenientemente en 1986 , sólo el $0,12 \%$ de los brasileños ${ }^{36}$.

\section{Brasil el caso más explosivo}

Es en Brasil donde el militarismo desarrollista tiene caracteres de mayor fragilidad.

A la debilidad de las Fuerzas Armadas en relación con el número de la población se agregan otros aspectos de gravedad.

Tradicionalmente, el sistema político brasileño se caracterizó por su gran flexibilidad. Gracias a su capacidad de compromiso, situaciones que en otros países provocaron hechos de violencia en Brasil fueron resueltas pacíficamente; la Independencia, la abolición de la esclavitud y el cambio de la monarquía a la república se produjeron sin derramamiento de sangre ${ }^{57}$. Su politica exterior se caracterizó por la habilidad de su diplomacia. Brasil creció geográficamente, a expensas de sus vecinos, sin guerras ${ }^{58}$.

El Ejército asumía el papel de "protector de la Constitución" y tenía una función de árbitro en las rivalidades políticas.

En la actualidad, las Fuerzas Armadas están siguiendo una política de exclusión. El compromiso ha sido desterrado como método e, incluso, las críticas moderadas al régimen son ahogadas por la fuerza. Los partidos políticos y las organizaciones sociales han sido eliminados y no se ha creado ninguna organización que los reemplace. En la práctica, el régimen no ha dado mayores pasos en torno a la creación de organismạs de masas que lo vinculen con el pueblo. EI partido oficial, ARENA, es una junta de notables dominada por las Fuerzas Armadas.

"56"El Ejército de Brasil. Sus problemas y perspectivas", en "Estrategia", op. cit., pp. 66-67.

${ }^{57}$ Para tener mayores antecedentes sobre la evolución política del Brasil, ver Helio Jaguaribe: Economic and Political Development. A Theoretical Approach and a Brasilian Case Study, Harvard University Press, Cambridge, Massachussets, 1968, pp. 97-193.

${ }^{58}$ Ver los artículos aparecidos en la revista Ercilla, $\mathrm{N}^{\mathrm{ax}}$ I $805, \mathrm{t} 806$. 
Alberto Sepúlveda / El militarismo desarrollista en América Latina

La política de modernización del gobierno militar ha sido poco coherente. Brasil, a diferencia de Argentina, es un país con serios problemas de integración geográfica y humana. El Sur tiene una economía industrial. EI Nordeste la clásica organización latifundista. En Brasil, la reforma agraria y las reformas de estructura son un requisito esencial para incorporar al mercado a la masa campesina. Sin embargo, el régimen ha pretendido expandir la industria sin reformas sociales, en base a un aumento de la exportación de productos industriales. Esta estrategia es limitada debido a la dificultad que tienen los productos industriales del Brasil para competir con las manufacturas europeas, norteamericanas o japonesas.

La oposición al régimen es considerable. En lọs centros urbanos los estudiantes y obreros no disimulan su malestar. La Iglesia está dividida, pero su sector más combativo y, en especial, aquella que está en contacto con el campesinado ha tomado una actitud crítica. Se han producido, en varias oportunidades, incidentes entre militares y sacerdo-tes.

Con posterioridad al golpe militar de 1964 , el sector "nacionalista" o de izquierda de las Fuerzas Armadas fue purgado. En Brasil, la oficialidad joven, la "línea dura", es un grupo de presión en pro de una política de mayor autoritarismo del régimen. En estas condiciones, las posibilidades de mayor moderación futura se esfuman.

Por último, han comenzado a aparecer ciertos síntomas de descomposición. La tortura a los opositores pareciera aplicarse en una escala creciente $^{59}$. La utilización de estos métodos normalmente implica un reconocimiento de debilidad $y$, en cierta medida, de temor. Además, acrecienta la oposición. En el caso cubano, la repulsa de la clase media a Batista, horrorizada por las torturas a los estudiantes, fue una de las causas importantes del éxito de Gastro. En el caso brasileno, la clase media urbana ha mantenido una actitud de neutralidad o de apoyo al Gobierno. Los torturados, en general, son dirigentes políticos o estudiantiles de extracción social burguesa. Muchos, son hijos de la clase media.

La política seguida por el grupo militar en Brasil ha contribuido a crearse un número creciente de adversarios y tiende paulatinamente a re-

\footnotetext{
${ }^{59}$ Ver también a Newton Garlos: "La tortura" en Ercilla, Santiago, $\mathrm{N}^{\circ} 1807$, p. 27.
} 
ducirse a las Fuerzas Armadas como único sector que apoya la política oficial.

Por último, la política de mayor moderación estadounidense y la revisión que se está llevando a cabo en ese país en el sentido de disminuir sus compromisos en el exterior y el desprestigio de las intervenciones como método político, debido al fracaso en Vietnam, constituye otro elemento a tomar en consideración ${ }^{60}$. Es improbable, en estos momentos, que Estados Unidos se decida a apoyar militarmente al Gobierno de Brasil ante la amenaza de un movimiento civil aunque fuera revolucionario.

En síntesis, en Brasil, se dan los siguientes elementos: Fuerzas Armadas débiles en relación con la población, falta de organismos de masas que apoyen al régimen, mayor autoritarismo que puede inducir, incluso a la oposición moderada a utilizar el camino de la violencia, falta de una política coherente de desarrollo, y oposición de sectores importantes de la tecnocracia, de la Iglesia, de los gremios y de los estudiantes. En Brasil puede darse, incluso, el esquema de una Revolución Agraria por parte de las masas campesinas del Nordeste.

Brasil es el eslabón más debil de las dictaduras desarrollistas y uno de los pocos lugares donde una revolución social puede desencadenarse en la década del 70.

${ }^{60}$ Para mayores informaciones acerca de la nueva orientación politica de Estados Unidos, en materia exterior, ver Richard Nixon: "United States Foreign Policy for the 1970's: A New Strategy for Peace", publicado en The New York Times, 19 de febrero de 1970, pp. 19-27. Para América Latina ver pp. 21-22. 